\title{
La paradoja entre democracia e identidad en América Latina
}

\author{
The paradox between democracy and identity in Latin America
}

\author{
Dr. Sebastián Andrés Bastías Arias \\ Universidad de Chile (Chile)
}

Recibido: 1 de diciembre 2011

Aceptado: 29 de diciembre 2011

\begin{abstract}
Resumen
Existe una peligrosa tendencia dominante hoy en día que consiste en considerar la democracia de una forma que la identifica casi exclusivamente con el triunfo del confuso concepto de identidad universal- casi como un imaginario de ciudadano universal- y la defensa de los derechos humanos, dejando a un lado el elemento de la soberanía popular, juzgándolo como un elemento obsoleto. Esto ha creado las condiciones para un déficit democrático que, dado el papel central desempeñado por la idea de soberanía popular en el imaginario democrático, ha tenido efectos devastadores sobre la lealtad entre identidad, ciudadanía e instituciones democráticas en Latinoamérica. A través de este planteamiento se desarrolla este planteamiento teórico.
\end{abstract}

\begin{abstract}
There is a dangerous dominant trend today that consists of considering democracy in a way that identifies it almost exclusively with the triumph of the confused concept of universal identity - almost as an imaginary of a universal citizen - and the defense of human rights, leaving it to one side the element of popular sovereignty, judging it as an obsolete element. This has created the conditions for a democratic deficit that, given the central role played by the idea of popular sovereignty in the democratic imaginary, has had devastating effects on the loyalty between identity, citizenship and democratic institutions in Latin America. Through this approach this theoretical approach is developed.
\end{abstract}

Palabras claves: Democracia, Identidad, Latinoamérica.

Keywords: Democracy, Identity, Latin America. 
Sumario: 1. Introducción 2. Globalización y estado; nación e identidad 3. Los límites de la identidad ciudadana 4. Bibliografía

Summary: 1. Introduction 2. Globalization and state; nation and identity 3 . The limits of citizen identity 4 . Bibliography

\section{Introducción}

América Latina se encuentra hoy en un doble proceso de transición desde las dos últimas décadas del siglo pasado. Proceso que no ha tenido homogeneidad alguna en los diferentes países latinoamericanos y que más bien responde al impulso de diferentes variables que es preciso llegar a diferenciar para no caer en la atractiva simplificación de ver esta transición como un producto concertado desde el Estado o la acción de un poder único hegemónico.

La transición a la cual nos referimos debe ser diferenciada como un doble proceso que nos lleva al resurgimiento de la clásica pregunta sobre la relación existente entre proceso democrático y desarrollo económico. La sociedad moderna junto con desplegar la diferenciación entre economía y política, siempre postuló (de modo afirmativo o crítico) cierta correspondencia entre ambas esferas. Cuando los países de América Latina se proponen armonizar "democracia política con crecimiento económico y equidad social están planteando un novedoso desafío" (Lechner, 1992). Hoy es bastante anacrónico el mantener la fidelidad hacia la premisa que durante mucho tiempo se planteó como panacea dual; mayor democratización es igual a mayor desarrollo económico. Es imposible mantener esa lógica, y continuar viendo que la democratización y el desarrollo económico - desde el liberalismo radicalizado- se encuentran como condiciones inseparables entre sí, y más específicamente el seguir propugnando que la profundización de una economía de mercado lograría una consolidación de los procesos democráticos (junto con mayores niveles de equidad socioeconómica) necesarios en los países latinoamericanos. Hoy no podemos continuar, al menos como se ha llevado hasta ahora, con la teorización de ver que la radicalización de una economía de mercado es la condición previa, y sine qua non, para una mejora en las condiciones necesarias para la democracia latinoamericana, como tampoco el creer en la 
sospecha de que la búsqueda ansiosa de la modernidad siguiendo los cánones occidentales se oponía a la verdadera identidad latinoamericana y que por eso ella fracasaba una y otra vez. Tal vez por cercanía del fenómeno, o tal vez por no dimensionar su impacto, la globalización no fue una variable de importancia en la discusión política durante largo tiempo $y$, hoy, debemos de considerarla como un hecho ineludible que incorporar en el debate; cuando esta ya está en nosotros.

\section{Globalización y estado; nación e identidad}

En El Capital, Marx había señalado, como una premonición profética, el proceso que tendría lugar durante el siglo XX y que se tendería a afianzar durante el siglo XXI:

Si es cierto que, de una parte, con el progreso de la producción capitalista, el desarrollo de los medios de transporte y comunicación acorta el tiempo de circulación para una determinada cantidad de mercancías, no es menos cierto que este mismo progreso y la posibilidad que el desarrollo de los medios de producción, comunicación y transporte entraña, supone, por el contrario, la necesidad, de trabajar para mercados cada vez más lejanos, en unas palabras, para el mercado mundial (Marx,1867).

La globalización es por sobre todo un fenómeno de "desaparición" de fronteras. Como ya lo hemos señalado; no es el producto de una acción concertada o revolucionaria sino por la imposibilidad de los Estados Nacionales de ejercer una influencia efectiva sobre la totalidad de sus economías una vez abrazada la premisa de concertar en manos no nacionales, principalmente, el control de las economías nacionales, que valga la aclaración obvia, se convierten en economías transnacionales.

Los fenómenos antes señalados nos invitan a repensar el mundo actual, al menos como la habíamos considerado hasta hace poco tiempo atrás, y replantearnos la conceptualización no sólo del Estado, sino también de cuestionarnos las concepciones de Nación, identidad o ciudadanía, con los impactos que esto significa a nivel de democracia y desarrollo en cada una de las realidades particulares de las naciones de América Latina dentro de un contexto global del que es cada vez más difícil de abstraerse sin señalar sus deficiencias, o al menos, 
de volver nuestra mirada de interrogación hacia el rol actual de la política, y específicamente del Estado, si es que aún es posible.

Al desconocimiento normal que tienen los contemporáneos, en cualquier periodo, respecto del marco objetivo y el sentido histórico de la época en que se inscribe y se entreteje su vida, los ciudadanos del siglo XXI podríamos oponer la excusa de que el escenario está "fuera de foco"; que vemos borroso, por lo pronto, lo que es borroso de suyo y, de ahí, poco descifrable. Para descifrarlo hacen falta códigos renovados, distintos a los que tenemos, aunque nada nos asegura que existan códigos adecuados cuando tanto ha perdido el orden que poseía. Lo que sí sabemos positivamente es que no pocas categorías analíticas básicas y claves se han vuelto precarias, confusas y disputables. Lo que existe hoy en el entorno político y, por qué no decirlo, en el entorno social, es una falta de control; un entorno que no se deja controlar.

Quizás nunca fue tan real la sentencia que dictó hace décadas atrás Jean Paul Sartre, en el sentido de que historia la hace el ser humano pero también con los otros seres humanos. Cuando el mundo o la sociedad pasan a ser incontrolables, y cuando, en virtud de su desprestigio, aunque sea bastante comprensible, las doctrinas y las ideologías importan mucho menos que las técnicas y los expertos profesionales, necesariamente surgen y cunden las alternativas de sentido, es decir, del sentido que debe dársele a la acción en que cada uno volcó su compromiso. Si no puede ser lo público, que sea lo privado; sino lo colectivo, lo individual: la vida debe tener sentido, algún sentido. Sentido que suele encontrarse cuando aquel sentido en el cual habíamos depositado nuestras esperanzas desaparece y resurgen las búsquedas imperiosas de caudillos, lideres, salvadores o etnias que habían sido olvidadas, para encontrar ahí, a modo de espejismo político aquello que la política tradicional no nos puede ofrecer a modo de respuesta; una identidad a la cual adherir o en la cual protegernos.

No todos ganan, frente a la erosión del Estado latinoamericano y su capacidad tradicional los espacios deben ser llenados para no caer en un caos total; espacios que son llenados ya no por un poder Estatal, sino por el poder de aquello que el Estado latinoamericano había 
podido cooptar; la identidad local, la etnia o el nacionalismo, o que había logrado hacer desaparecer temporalmente; el populismo, el caudillismo o la demagogia. La gran afirmación triunfante de Fukuyama sobre el fin de la historia y la desaparición de las ideologías olvidó un elemento clave: no todos han sido beneficiados, no todos están felices con el actual proceso:

La identidad cultural, a pesar de ser un concepto central en las Ciencias Sociales, ha sido un tema problemático para esta disciplina. Ha habido dudas acerca de la realidad de las unidades etnográficas de estudio asumidas: las culturas. Hay una aparente incongruencia entre la persistencia de la idea de grupos étnicos identificables, y por lo menos parcialmente cerrados, en muchas culturas y un mundo que las intenta desechar (COCCO, 2001).

Desde el liberalismo ortodoxo, Vargas Llosa señaló que

esta internacionalización generalizada de la vida es, acaso, lo mejor que le ha pasado al mundo hasta ahora. Gracias a ella, los países pobres pueden dejar de serlo, insertándose en aquellos mercados donde siempre podrán sacar provecho a sus ventajas comparativas, y los países prósperos alcanzar nuevos niveles de desarrollo tecnológico y científico. Con la desaparición de la polarización política, la posibilidad de que este proceso se acelere hasta la articulación de todos los particularismos nacionales en una vasta y flexible civilización global, bajo el signo de la democracia política, el respeto a los derechos humanos y a la libertad individual, ha dejado de ser una utopía. (Vargas Llosa, 1994, p.214)

Pero existen otros que siendo liberales critican el desorden caótico presente en la globalización, haciendo un llamado urgente a poner orden: “¿Por qué Estados Unidos no puede en la actualidad asemejarse a lo que fue el Reino Unido hace cien años? Permitir que la globalización económica continúe procediendo sin una mano imperial directiva es peligroso y puede llegar a juzgarse en el futuro como una abdicación necia de responsabilidad" (Vargas Llosa, 1994).

La globalización ha creado las condiciones necesarias para que algunos vean en ella a la globalización de las oportunidades, las riquezas, sin embargo se olvidan, al pensarlo como 
un proceso unilateral, que esto también posibilita la globalización de los problemas cuando las oportunidades o las ventajas comparativas, sencillamente no existen. En el escenario actual de la política, por lo tanto, considerar el triunfo de la democracia como el triunfo de la globalización es hacer un ejercicio de simplificación en extremo, olvidando que las políticas nacionales responden a necesidades nacionales y que, por ende, los efectos de determinadas prácticas teóricas no responderán de la misma manera en diferentes contextos y realidades. Más aun cuando los problemas de soberanía y ejercicio de políticas públicas se ven cada vez más cuestionados e incapacitadas de llevarse a cabo; o cuando vemos que la política ha cambiado pero que los viejos axiomas de la política se encuentran aún vigentes a la manera de un espejismo quijotesco. Como reconoce Milton Friedman respecto a este supuesto mundo global igualitario:

Somos una gran nación, los líderes del mundo libre. Mal podemos permitirnos exigir a Hong Kong y Taiwán la imposición de cupos a los productos textiles para proteger nuestra industria textil a expensas de los consumidores norteamericanos y de los trabajadores chinos de Hong Kong y Taiwán. Hablamos de manera entusiasta de las virtudes de libertad de comercio, mientras utilizamos nuestro poder político y económico para inducir a Japón a que reduzca sus exportaciones de acero y televisores (Friedman, 1991)

Si tan sólo cambiamos el nombre de los países dentro de la cita anterior podremos hacer un pequeño ejemplo más clarificador con tan sólo pensar, en silencio, nuestra Latinoamérica actual.

Mientras que el marxismo tradicional era internacional, la izquierda actual se vuelve antiglobalización. La razón es debido a que la internacionalización marxista era por y para el triunfo del socialismo, en cambio la globalización se ha convertido en el triunfo material del capitalismo mundial. Como ha señalado Forrester: "Son tiempos extraños en que el proletariado se esfuerza por recuperar su condición inhumana. La Internacional relegada al rincón de los objetos en desuso, las canciones olvidadas, parece resurgir muda, sin letra ni música, entonada en silencio por otro bando" (Forrester,1994). Sin embargo desde la 
izquierda más "lucida" se reconoce la inevitabilidad de abstraerse a la globalización y los desafíos que esta significa para la política de los diferentes Estados puestos en un jaque inevitable que es necesario enfrentar. Como ha señalado Giddens: "hay quienes afirman que la globalización ha llegado a un punto de hacer irrelevante el Estado nacional, que los gobiernos son irrelevantes, que el mercado global es el único dueño y señor, que lo único que pueden hacer los gobiernos es reducir su tamaño y suprimirse, dejar paso libre. La política local ya no es relevante en un mundo dominado por las fuerzas del mercado global" (Giddens, 1998). La perspectiva propuesta por Giddens no es nada nuevo y podemos concebirla como una visión bastante cercana a la postulada por los liberales durante mucho tiempo con la creación de un modus vivendi a nivel global o, siguiendo a Shumpeter, de un modus procedendi que regule el conflicto entre los diferentes puntos de vista. De ahí la perspectiva actual, generalmente aceptada, de ver la democracia como forma procedimental, y neutral, con respecto a cualquier particular conjunto de valores, como simple método para tomar las pocas decisiones públicas que son posibles de tomar.

\section{Los límites de la identidad ciudadana}

Hoy, debemos de reconocer que los límites de la ciudadanía se han puesto en discusión, discusiones que borran de un golpe la relación entre ciudadanía e identidades nacionales -y todo lo que esto significa- como formas interdependientes. Muchos autores han abrazado los postulados simplistas de argumentar que en una era de globalización es imposible que la ciudadanía quede confinada a los límites de sus Estados nación; que la ciudadanía debe volverse transnacional. David Held, por ejemplo, aboga por el advenimiento de una ciudadanía cosmopolita, y afirma la necesidad de un derecho democrático global al que puedan apelar los ciudadanos cuyos derechos hayan sido violados por sus propios Estados (Held, 1995). Richard Falk, por su parte, contempla el desarrollo de ciudadanos peregrinos cuyas lealtades estarían vinculadas a la invisible comunidad política de sus esperanzas y sueños (Falk, 1995). 
Otros teóricos, en particular aquellos que muestran un compromiso mucho más férreo hacia un concepto de ciudadanía más cívico y republicano, han manifestado sus dudas con respecto a estas perspectivas, considerándolas peligrosas para la mantención y consolidación de las formas democráticas de gobierno. Sostienen que el Estado nacional es el locus necesario de la ciudadanía, y que existe, por lo tanto, algo inherentemente contradictorio en la propia idea de una ciudadanía cosmopolita.

Existe una peligrosa tendencia dominante hoy en día que consiste en considerar la democracia de una forma que la identifica casi exclusivamente con el triunfo del confuso concepto de identidad universal- casi como un imaginario de ciudadano universal- y la defensa de los derechos humanos, dejando a un lado el elemento de la soberanía popular, juzgándolo como un elemento obsoleto. Esto ha creado las condiciones para un déficit democrático que, dado el papel central desempeñado por la idea de soberanía popular en el imaginario democrático, ha tenido efectos devastadores sobre la lealtad entre identidad, ciudadanía e instituciones democráticas en Latinoamérica.

En todas las sociedades existe un conjunto de imágenes mentales con las que se clasifica a las personas, sobre la base de rasgos individuales o sociales no verificados y extrapolados. Estos rasgos asignados, además de ser particulares en cada grupo social y en cada sociedad, en el contexto de la cultura global se están universalizando. Se está produciendo una homogeneización y uniformalización paulatina que hace que estas imágenes mentales creen modelos de referencia, de aspiración o rechazo, en función de la consideración que tales rasgos. Estas posiciones o conductas sociales tienen lo que hemos señalado como una suerte de identidad universal. Al respecto, y podríamos decir a contrapelo de Habermas, Cocco señala:

En el interior de las "nebulosas" culturales y sociales los actores respectivos manifiestan escogencias de identificación, variadas en su naturaleza, en su intensidad y en su nivel, en función de las situaciones que ponen en juego, específicamente, las formas de las relaciones mantenidas con la sociedad englobante y sus instituciones, por un lado; con los grupos o los individuos con los cuales la comunicación y los 
intercambios de bienes y servicios son intensos, por otro lado. Por lo tanto, en ese sentido, la identidad se construye más en la relación con el otro y con la diferencia, que en la relación consigo mismo y con lo idéntico, definido todo a la vez por el otro y contra el otro. En resumen, es un sentimiento, una vivencia cotidiana, un concepto que se define y redefine fundamentalmente por oposición al otro, a los otros, como diferencia (COCCO, 2003).

La propia legitimidad de la democracia se basa en la idea de soberanía popular y sería un grave error considerar que ha llegado el momento de renunciar a ella. Las instituciones democráticas no deberían de considerarse como un elemento garantizado; siempre es necesario robustecerlas y defenderlas. Esto exige aprehender su dinámica específica local y reconocer las tensiones que derivan de sus distintas lógicas. Sólo aceptando la paradoja democrática, una tensión constante entre la identidad local- nacional y la identidad universal como dos lógicas diferentes, podremos considerar el modo de enfrentarnos y convivir con ellas políticamente (Tugendhat, 1996) Por ello es vital para la política latinoamericana el comprender que la democracia liberal actual es la articulación entre dos lógicas que, en última instancia, son incompatibles entre sí, y que no hay forma de reconciliarlas sin imperfección. Esta es la razón de que el régimen liberal democrático haya sido objeto de constantes enfrentamientos, enfrentamientos que han sido los propulsores de los desarrollos, cambios y crisis políticas e históricas. La tensión entre sus componentes sólo puede estabilizarse temporalmente estableciendo hegemonías temporales de alguno de sus componentes constitutivos por sobre otro, u otros. Y es que, hasta hace poco tiempo atrás, la existencia de fuerzas opuestas se reconocía abiertamente, y sólo en nuestros días, o más bien a partir de la última década del siglo $X X$, cuando la propia idea de una posible alternativa al orden existente ha quedado sin crédito alguno, la estabilización lograda durante el último periodo de hegemonía de la globalización aparece prácticamente libre de todo cuestionamiento. Las naciones y las culturas nacionales son construcciones continuamente imaginadas, inventadas, cuestionadas y transformadas por individuos, por el Estado y por el flujo global de informaciones. Hoy, como una práctica social, la misma concepción de nación, 
inmersa dependientemente del concepto de nacionalidad racional y, por ende universal, nos aparece como algo dado, necesario y natural.

\section{Bibliografía}

Cocco, G. (2001). Valorizzare il capitale umano d'impresa: Il talento delle persone come competenza distintiva delle imprese. Etas libri.

Cocco, G. (2003). Trabajo y ciudadanía: producción y derechos en la era de la globalización. España, Xátiv: LÚllal.

Falk, R. A. (1995). On humane governance: Toward a new global politics. Penn State Press.

Giddens, A. (1998). La transformación de la intimidad. Ediciones Cátedra.

Held, D. (1995). Democracy and the global order: From the modern state to cosmopolitan governance. EE.UU.: Stanford University Press.

Forrester, J. W. (1994). System dynamics, systems thinking, and soft OR. System dynamics review, 10(2-3), 245-256. https://doi.org/10.1002/sdr.4260100211

Friedman, D. (1991). Evolutionary games in economics. Econometrica. Journal of the Econometric Society, 637-666. Recuperado de https://www.jstor.org/stable/2938222?seq=1\#metadata_info_tab_contents

Marx, K. (1867). 1976. Capital: A critique of political economy, 1.

Tugendhat, E. (1996). Identidad, Personal, Nacional y Universal. Ideas y Valores, 100. Bogotá: Colombia. Recuperado de https://es.scribd.com/doc/55583218/ldentidad-PersonalNacional-y-Universal-Ernst-Tugendhat

Vargas Llosa, M. (1994). Desafíos a la Libertad. Madrid: Editorial El País-Aguilar.

\section{Forma de citar este artículo en bibliografías}

BASTÍAS ARIAS, S. A. (2011): "La paradoja entre democracia e identidad en América Latina", en Revista PANGEA, 2, páginas 128 a 137. Red Académica Iberoamericana de Comunicación. Recuperado el de de 2 de: www.revistapangea.org 